\title{
Wear research of railway wheelset profile by using computer simulation
}

\author{
Lukáš Smetanka ${ }^{1, *}$, Pavol Št’astniak ${ }^{1}$, Jozef Harušinec ${ }^{1}$ \\ ${ }^{1}$ University of Žilina, Faculty of Mechanical Engineering, Department of Transport and Handling \\ Machines, Univerzitná 8215/1, 01026 Žilina, Slovak Republic
}

\begin{abstract}
The wear of rails and wheels is important problem in rail traffic. The change of the shape of the wheel profile has not only a great influence on the dynamic properties of the vehicle (like stability, safety by passing curved tracks, etc.), but also affects the ride comfort of passengers and environmental insults, in extreme cases it can cause rail derailment. One of the ways to predict these undesired conditions are computer aided simulation analyzes. In this article are presented assessments of wheel profile wear by Archard wear law in Simpack simulation software, when is railway vehicle driving at different velocities.
\end{abstract}

Keywords: wear research, rail vehicle, computer tools

\section{Introduction}

The dynamic behavior of rail vehicles on the track is significantly affected by the interaction between the wheel and the rail. In the depth of the examined issue is an understanding of the contact between the wheels and the rails. There are problems in this more in-depth study which stand alone are broad scientific areas. One of the most important areas with significant influence on geometry change and thus the change in contact conditions is undoubtedly the wear and related geometry changes of one part of the contact pair or both, such as the corrugation of the track and its irregularity, changes in friction and slip ratio or changes in vertical and longitudinal forces of the contact pair, etc. The impact of wear certainly affects also the acoustic and vibrational expression of the car on the rail, which, by increasing the negative side, devastates the environmental environment around the tracks $[1,2]$.

Wear belongs to the degradation processes in which the material is discharged from the surface of one or both of the contact surfaces of rigid bodies which are in relative movement. Relative movement of the contact surfaces can directly lead to destroying of the component, or to damage of surface treatment or to surface damage, resulting in subsequent destruction of the component. According to STN 015050 the wear proves as removing or displacing individual particles from the worn surface by mechanical effects, or accompanied by other influences (chemical, electrical etc.). The characteristic of the relative movement between the two entities in contact defines the wear process, in general

\footnotetext{
*Corresponding author: pavol.stastniak@fstroj.uniza.sk

Reviewers: Maciej Bodnicki, Janusz Mielniczuk
} 
it can be divided into the following areas: adhesion, abrasive, corrosive, erosive, fatigue, cavitation and vibrational wear. During the operation of the railway transport, both wheel and rail wear occur, either due to normal operation or failure. With regard to the type of wear, the wear of rolling stock is based on the character of friction and also on the basis of cyclic fatigue. Over time the process of fatigue become separate scientific area named RCF (Rolling Contact Fatigue) [3-6].

\section{Archard wear law in SIMPACK software}

According to several literary sources, there are three main trends in the development of the wear, patterns from the middle to the end of the twentieth century and they are: based on empirical approach, based on a contact mechanics approach and based on a reflex mechanics approach. An irreplaceable and important factor in wear is friction. The hypothesis suggests:

$$
\mathrm{F}_{\mathrm{F}}=\mu \cdot \mathrm{F}_{\mathrm{N}}
$$

where:

$-F_{F}$ is frictional force,

- $\mu$ is frictional coefficient,

- $F_{N}$ is applied normal force.

This frictional equation is based on two basic assumptions, first is approach that the stress distribution is independent to normal load and second that the applied load is proportional to real contact area.

We knows more wear laws which were then development and modified, but all of them are based on basic theories from authors like Reye (1860), Tabor (1939), Holm (1946) a Archard (1953). [7,8,9]

The supplement for wear determination is in SIMPACK software embedded to the module SIMPACK RAIL, it is therefore the determination of wear in the contact wheel-rail pair, where are the contact stresses solved by using the Kalker method named FASTSIM. $[9,10]$ The developer motivated the application of supplement mainly to the issue of safety and maintenance, as is known, wheels and rails are subjected to wear and rolling contact fatigue (RCF) throughout their lifecycle, due the forces acting during frequent rail traffic. Considering that there are many different waste laws and RCF, the module has an open structure that makes it possible to implement the necessary changes to achieve the preferred type of wear. The SIMPACK software offers two different laws of wear and tear for simulation: Archard wear law and Krause/Poll wear law.

Archard wear law is for the SIMPACK software based on the following equation:

$$
\mathrm{V}=\frac{\mathrm{N} \cdot \Delta \mathrm{s}}{\mathrm{H}} \cdot \begin{array}{llc}
\mathrm{k}_{1} \ldots \text { if } \ldots & \mathrm{p}>\mathrm{f} \cdot \mathrm{H} & \text { seizure } \\
\mathrm{k}_{2} \ldots \text { if... } & \mathrm{p} \leq \mathrm{f} \cdot \mathrm{H} \wedge \mathrm{v}_{\mathrm{s}} \leq \mathrm{v}_{1} \quad \text { mild }-1 \\
\mathrm{k}_{3} . . \text { if...p } \leq \mathrm{f} \cdot \mathrm{H} \wedge \mathrm{v}_{1}<\mathrm{v}_{\mathrm{s}} \leq \mathrm{v}_{2} & \text { severe } \\
\mathrm{k}_{4} \ldots \text { if } \ldots \quad \mathrm{p} \leq \mathrm{f} \cdot \mathrm{H} \wedge \mathrm{v}_{2}<\mathrm{v}_{\mathrm{s}} & \text { mild }-2
\end{array}
$$

where:

- $V$ - wear volume $\left[\mathrm{m}^{3}\right]$,

- $N$ - normal contact force [N],

- $\Delta s$ - sliding distance $[\mathrm{m}]$,

- $H$ - hardness of the softer material in contact pair [MPa],

- $k_{l}-k_{4} .$. wear coefficients, (seizure, mild 1, severe and mild 2) [ - ], 
- $p$ - contact pressure $[\mathrm{MPa}]$,

- $f$ - hardness fraction $H$ over which destruction occurs (seizure),

$-v_{s}-$ sliding (relative) velocity $[\mathrm{m} / \mathrm{s}]$,

- $v_{l, 2}$ - boundary velocities, in which the wear coefficients are changing from mild 1 to severe and back to mild $2[\mathrm{~m} / \mathrm{s}]$.

The sliding distance is calculated from actual output step. The normal force, pressure and sliding (relative) velocity are selected from wheel-rail contact elements. The typical values for wear coefficients are used in literature like: $\mathrm{k}_{1}=300-400 \cdot 10^{-4}$, $\mathrm{k}_{2} \approx \mathrm{k}_{4}=1-10 \cdot 10^{-4}$ and $\mathrm{k}_{3}=30-40 \cdot 10^{-4}$ (Fig. 1).

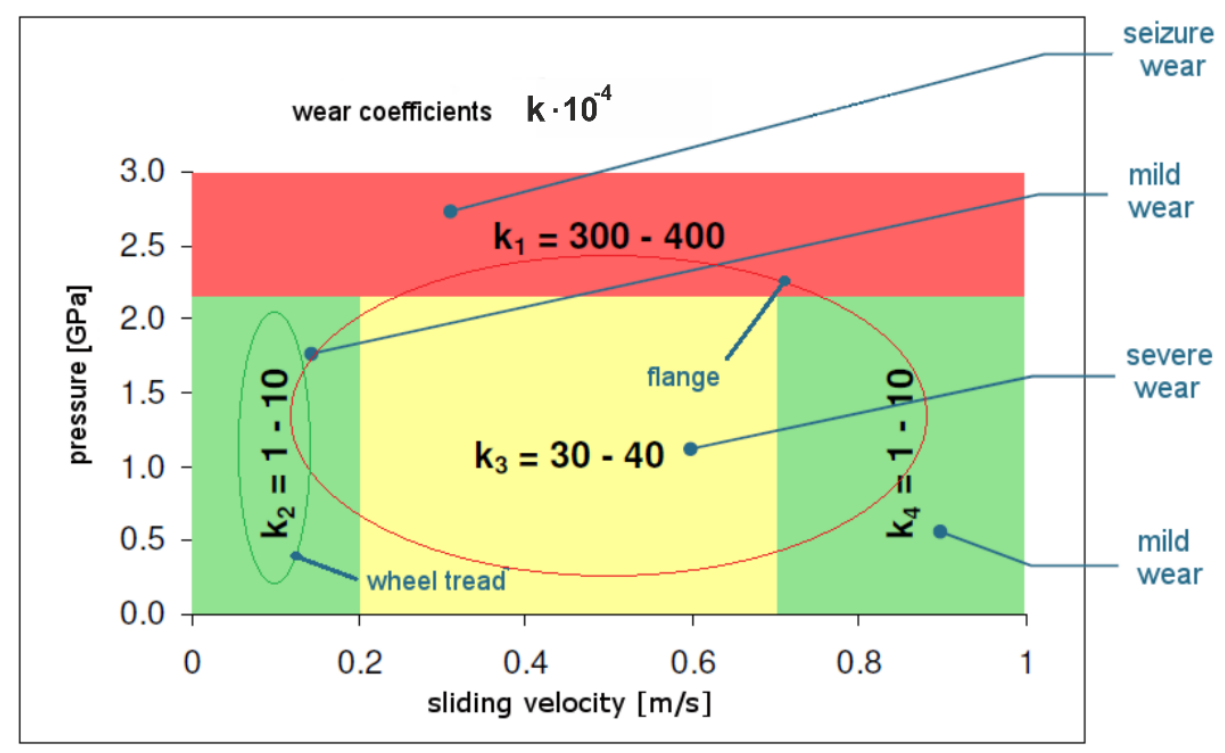

Fig. 1. Wear coefficients

\section{Preparation of simulation}

From the point of view of simulation of wear it was necessary to create the most accurate model of the vehicle so that the simulation showed the best possible match with the actual vehicle on the real track. The SIMPACK software has been selected as a suitable solution for this simulation, which enables us to achieve the desired behavior of the vehicle with its characteristic features. The software allows for a quick and comfortable assembly of the MBS (Multibody Simulation) model of a rail vehicle that meets the wheel-rail contact specifications.

\subsection{Computational vehicle model}

The computational model is characterized by vehicle parameters, geometric and weight parameters, elastic parameters of springs and dampers, and the like. Additionally, they are the parameters of the contact between wheel and rail and the track parameters. [10-14] This article presents results for one vehicle model (Fig. 2) Model A.

The weight parameters, elastic parameters of springs and dampers and geometrical parameters of the vehicle are described in following tables (Tab. 1, Tab. 2, Tab. 3). 


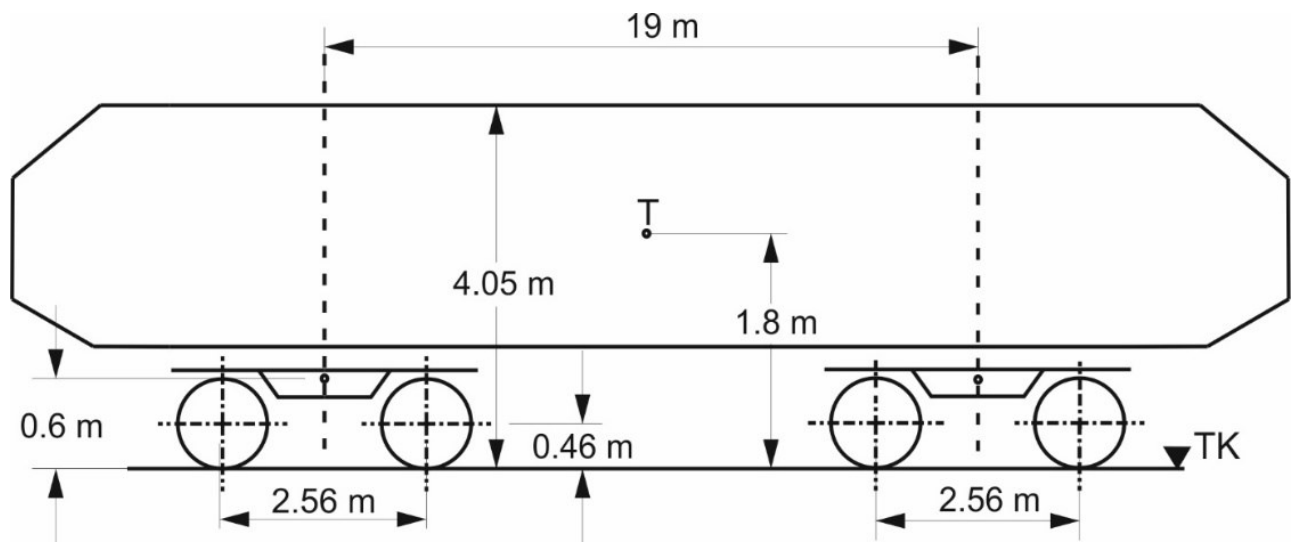

Fig. 2. Schematic sketch of the vehicle (Model A)

Table 1. The weight parameters (Model A)

\begin{tabular}{|c|c|c|c|c|}
\hline & $\mathbf{m}[\mathbf{k g}]$ & $\mathbf{I}_{\mathbf{x x}}\left[\mathbf{k g} \cdot \mathbf{m}^{\mathbf{2}}\right]$ & $\mathbf{I}_{\mathbf{y}}\left[\mathbf{k g} \cdot \mathbf{m}^{2}\right]$ & $\mathbf{I}_{\mathbf{z z}}\left[\mathbf{k g} \cdot \mathbf{m}^{2}\right]$ \\
\hline Wheelset & 1813 & 1120 & 112 & 1120 \\
\hline Bogie Frame & 2615 & 1722 & 1476 & 3067 \\
\hline Vehicle Casing & 32000 & 56800 & 1970000 & 1970000 \\
\hline
\end{tabular}

Table 2. Elastic parameters of springs and dampers (Model A)

\begin{tabular}{|c|c|c|c|}
\hline Springing & $\mathbf{c}_{\mathbf{x}}\left[\mathbf{N} \cdot \mathbf{m}^{-\mathbf{1}}\right]$ & $\mathbf{c}_{\mathbf{y}}\left[\mathbf{N} \cdot \mathbf{m}^{-\mathbf{1}}\right]$ & $\mathbf{c}_{\mathbf{z}}\left[\mathbf{N} \cdot \mathbf{m}^{-\mathbf{1}}\right]$ \\
\hline Primary Springing & 31391000 & 3884000 & 1220000 \\
\hline Secondary Springing & 160000 & 160000 & 430000 \\
\hline Damping & $\mathbf{d}_{\mathbf{x}}\left[\mathbf{N} \cdot \mathbf{s} \cdot \mathbf{m}^{-\mathbf{1}}\right]$ & $\mathbf{d}_{\mathbf{y}}\left[\mathbf{N} \cdot \mathbf{s} \cdot \mathbf{m}^{-1}\right]$ & $\mathbf{d}_{\mathbf{z}}\left[\mathbf{N} \cdot \mathbf{s} \cdot \mathbf{m}^{-\mathbf{1}}\right]$ \\
\hline Primary Springing & 15000 & 15000 & 4000 \\
\hline Secondary Springing & 32000 & 32000 & 20000 \\
\hline
\end{tabular}

Table 3. The geometrical parameters of vehicle (Model A)

\begin{tabular}{|l|c|c|c|}
\hline \multicolumn{1}{|c|}{ Parameter } & Description & Value & Dimension \\
\hline $\begin{array}{l}\text { The transverse distance of activities of } \\
\text { primary springing and damping }\end{array}$ & 2 & {$[\mathrm{~m}]$} \\
\hline $\begin{array}{l}\text { The transverse distance of activities of } \\
\text { secondary springing and damping }\end{array}$ & & 2 & {$[\mathrm{~m}]$} \\
\hline The distance of rotary pin of bogies & & 19 & {$[\mathrm{~m}]$} \\
\hline The wheelbase of bogies & & 2.56 & {$[\mathrm{~m}]$} \\
\hline Nominal wheel diameter & 0.92 & {$[\mathrm{~m}]$} \\
\hline $\begin{array}{l}\text { Height of center of gravity for wheelset } \\
\text { above TK }\end{array}$ & 0.46 & {$[\mathrm{~m}]$} \\
\hline $\begin{array}{l}\text { Height of center of gravity for bogie frame } \\
\text { above TK }\end{array}$ & & 0.6 & {$[\mathrm{~m}]$} \\
\hline $\begin{array}{l}\text { Height of center of gravity for vehicle } \\
\text { casing above TK }\end{array}$ & 1.8 & {$[\mathrm{~m}]$} \\
\hline Height of the primary springing above TK & & 0.46 & {$[\mathrm{~m}]$} \\
\hline $\begin{array}{l}\text { Height of the secondary springing above } \\
\text { TK }\end{array}$ & & 0.52 & {$[\mathrm{~m}]$} \\
\hline Wheel profile & $\mathrm{S} 1002$ & & \\
\hline Rail gauge & $\mu$ & 0.4 & {$[-]$} \\
\hline Frictional coefficient & & 1435 & {$[\mathrm{~mm}]$} \\
\hline
\end{tabular}




\subsection{Track parameters}

The model track consists from the straight sections, clothoid transitions and superelevations segments in the curves of the track. Fig. 3 shows the horizontal track profile, which were by wear simulation used with aim to determine the wear of the vehicle on the track. The length of the model track is $400 \mathrm{~km}$ and from picture is clearly that the profile is very diverse. The track consists from 24 right and 24 left curves of track, the vehicle runs in straight track overall $366 \mathrm{~km}$ and $44 \mathrm{~km}$ in curves of track. The superelevations of the outer ribbon in the curves of track are for ech curve of another value. The model track it is not considered like ideally horizontally and vertically straight, in the simulation is considered lateral and vertical irregularities on track too. The irregularities cause the excitations of dynamics system by driving the vehicle on the track and are mostly stochastic.

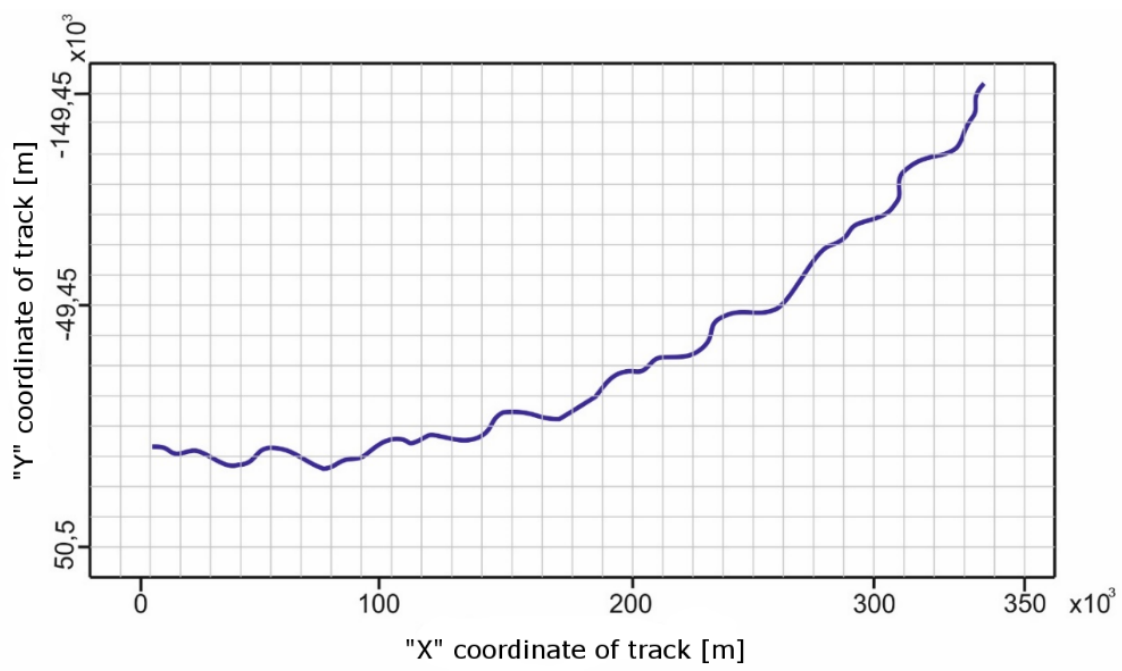

Fig. 3. Horizontal track profile

Fig. 4 shows the rail profiles which were used by wear simulations. All the analyzes are comply to condition, that the vehicle was traveling along track where the rail profile was defined by standard (UIC 60 profile) with cant of 1:40, or the track profile really measured on the track, the profile S 91700_16 with the cant of 1:20.
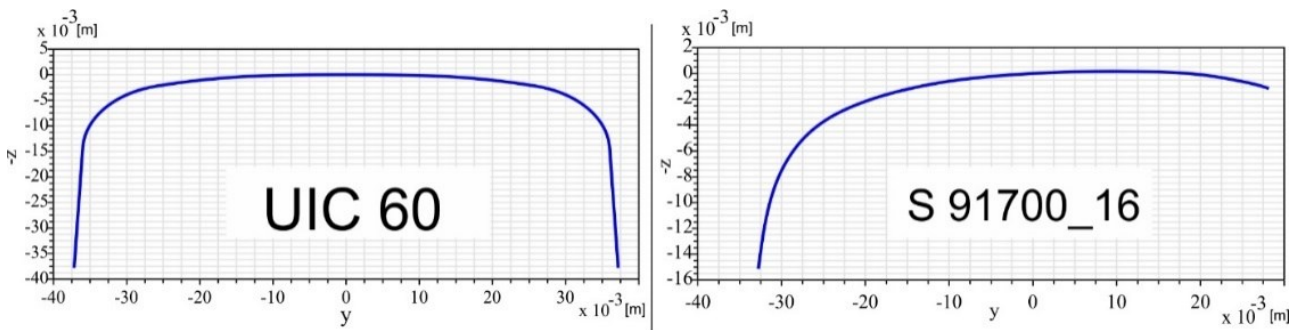

Fig. 4. The rail profiles 


\section{Simulations and evaluation of results}

In the simulations of railway wheel wear we focused on the impact of vehicle velocity change. The simulations was performed in two variants, by driving the vehicle Model $A$ on the track with rail profile UIC 60 or rail profile S $91700 \_16$ and the vehicle velocity was different in three independent variations. The velocity was set at $15 \mathrm{~m} / \mathrm{s}$ which is $54 \mathrm{~km} / \mathrm{h}$, $22.5 \mathrm{~m} / \mathrm{s}$ which is $81 \mathrm{~km} / \mathrm{h}$ and to $30 \mathrm{~m} / \mathrm{s}$ which is $108 \mathrm{~km} / \mathrm{h}$. In the final view was performed 10 analysis $(10 \mathrm{x} 400 \mathrm{~km}=4000 \mathrm{~km}$ long track) for each velocity and rail variant, together it was 60 analysis.

On following figures (Fig. 5 and Fig. 6) are displayed the curves of wear depth for two rail variants (UIC 60 and S 91700_16) and for three different velocities, $15 \mathrm{~m} / \mathrm{s}$ (green line), $22.5 \mathrm{~m} / \mathrm{s}$ (red line) and $30 \mathrm{~m} / \mathrm{s}$ (blue line). The curves of wear depth are displayed for each wheelset of vehicle Model $A$ but only for right wheels. The curves for left wheels had the similar character. For understanding the time aspect of the calculation, one simulation on $400 \mathrm{~km}$ long track by the $15 \mathrm{~m} / \mathrm{s}$ vehicle velocity took 15 hours computer time (CPU Time).
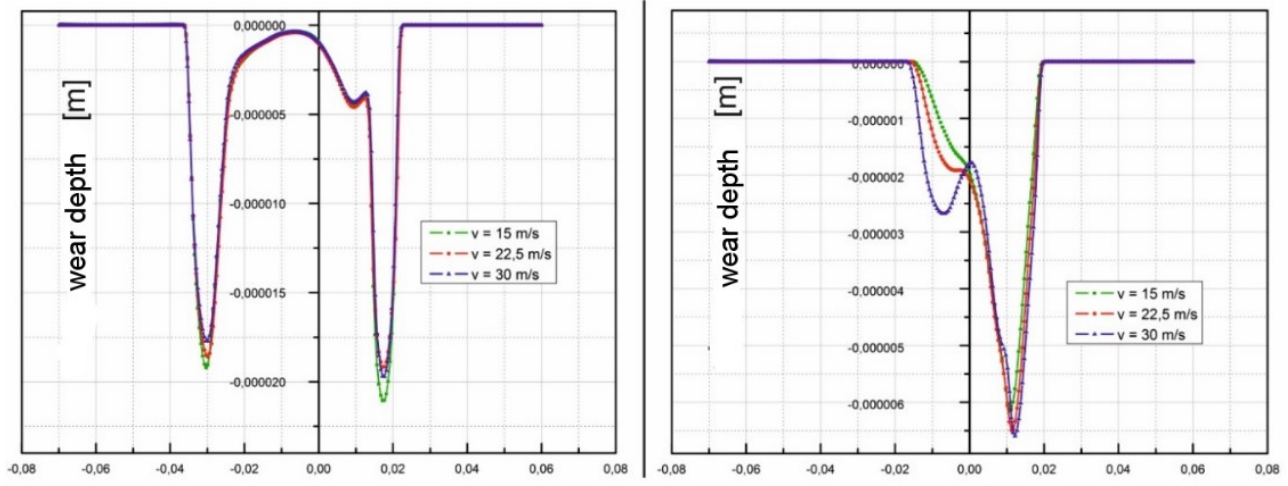

"y" coordination of wheel profile [m]

"y" coordination of wheel profile [m]

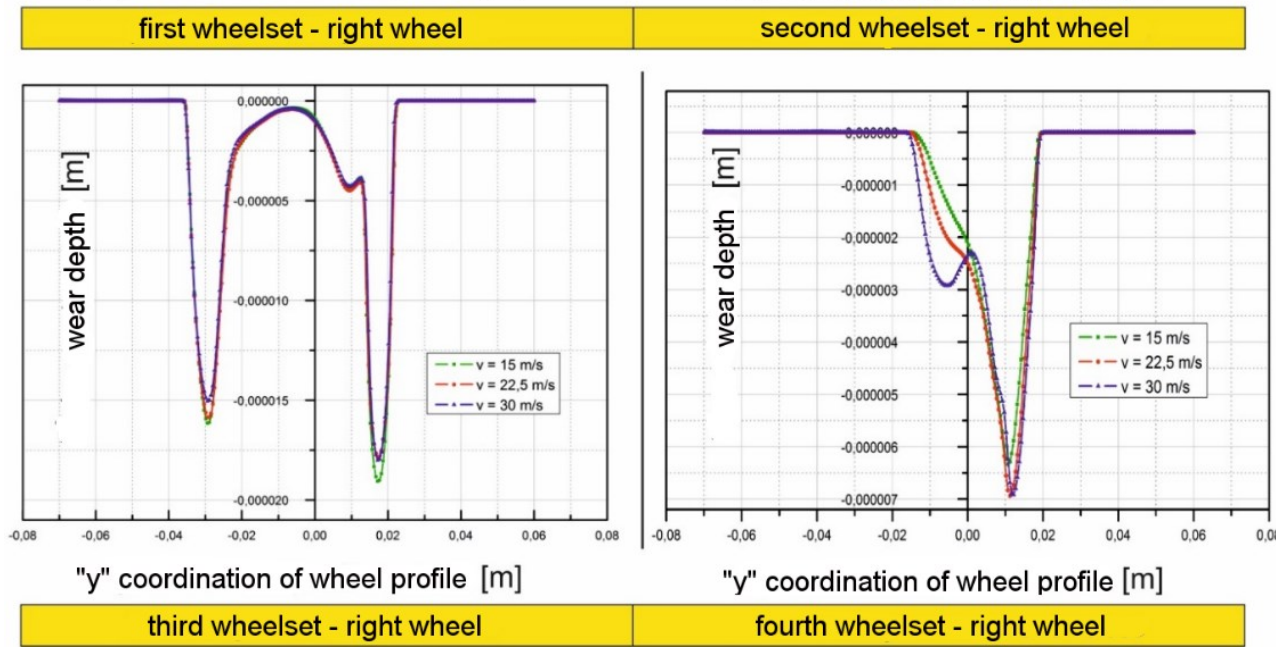

Fig. 5. The wear depth for Model $A$ by driving on the $S 91700 \_16$ rail profile 


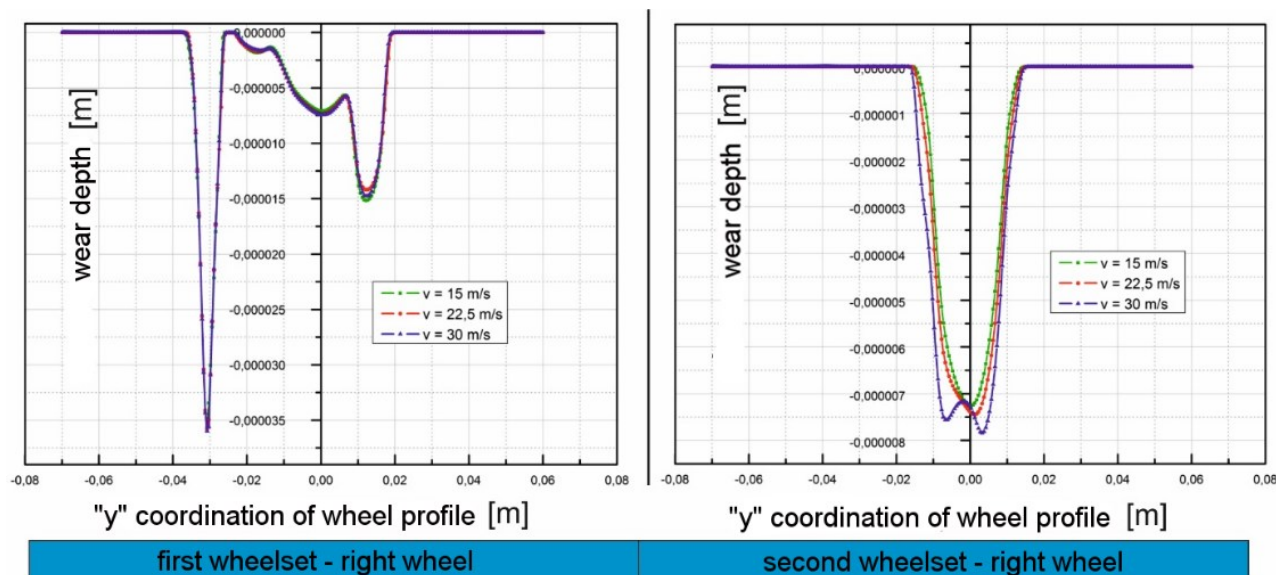

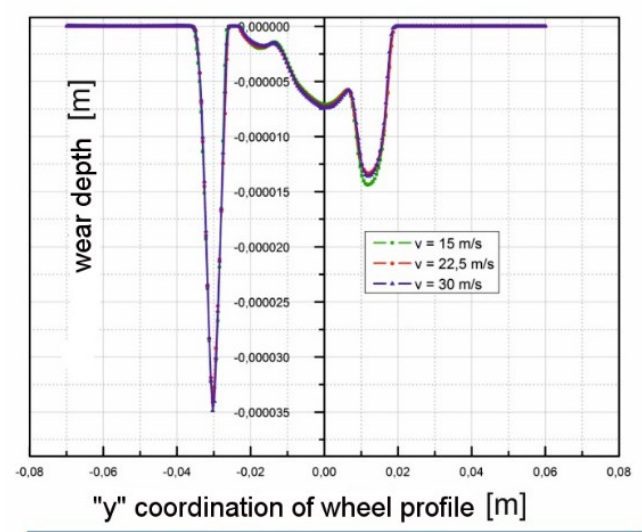

third wheelset - right wheel

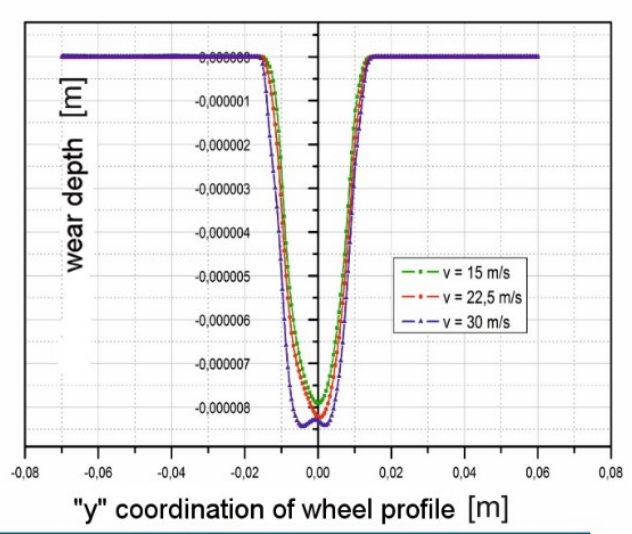

fourth wheelset - right wheel

Fig. 6. The wear depth for Model $A$ by driving on the UIC 60 rail profile

The figures shown, it is possible to notice the similar character of curves on the first and third wheels, while on the second and fourth wheels are the differences in the curves more visible. In the first and third wheels, differences are visible especially in the areas of the curve peaks, while with the second and fourth wheels are curves with higher driving velocity wider. The presence of peaks in the curves of the wear depth is caused by the passage of the vehicle on the curves of track where, as is generally known, the contact surface is changing. The contact area is generally smaller and the contact stress is higher than at the given position than in the centered position of the wheel in the rail.

Since it is not entirely clear how the velocity change factor affects to the wear depth, we decided use the volume criterion (Fig. 7, Fig. 8). 


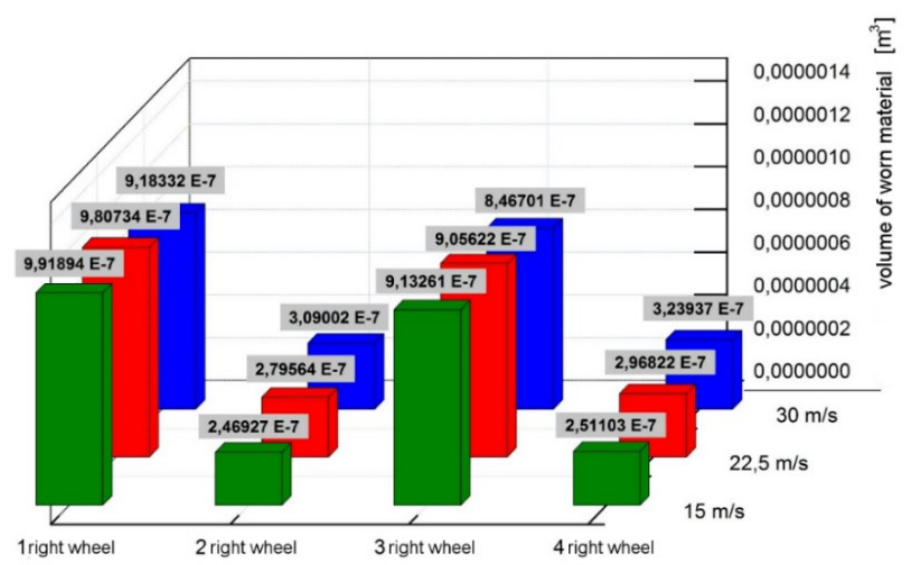

Fig. 7. The volumes of worn material for Model A by driving on the $S 91700 \_16$ rail profile

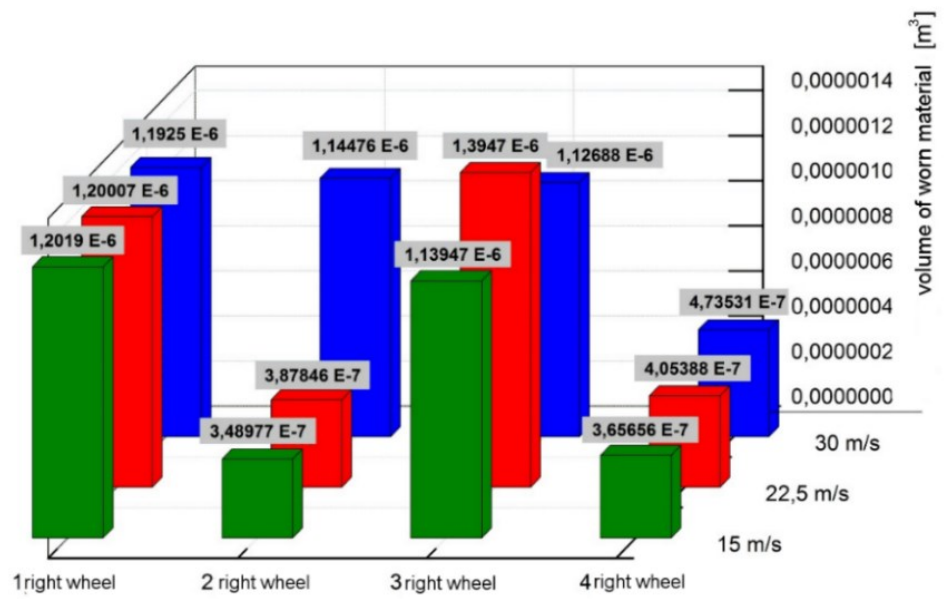

Fig. 8. The volumes of worn material for Model A by driving on the UIC 60 rail profile

\section{Conclusion}

This article is aimed to determination of railway wheel wear by driving on the track. The wear simulations were focused to influence of the change of vehicle velocity on the change of wear depth for railway wheel, which were driven at two possible rails profile, UIC 60 or S 91700_16. The simulations were performed in six independent variants, where total traveled distance for one variant was $4000 \mathrm{~km}$. The vehicle velocity was set to $15 \mathrm{~m} / \mathrm{s}, 22.5$ $\mathrm{m} / \mathrm{s}$ and $30 \mathrm{~m} / \mathrm{s}$. On the displayed figures are compared wear depth and volumes of worn material for individual variants.

The work was supported by the Cultural and Educational Grant Agency of the Ministry of Education of the Slovak Republic in project No. KEGA 077ŽU-4/2017: Modernization of the Vehicles and engines study program. The work was also supported by the project No. APVV-0842-11: Equivalent railway operation load simulator on the roller rig and VEGA Nr. 1/0927/15: Research of the use of alternative fuels and hybrid drives on traction vehicles with aim to reduce fuel consumption and air pollutants production.

Research-Educational Center of Rail Vehicles (VVCKV) 


\section{References}

1. I. I. Argatov, Y. A. Fadin, Mathematical Modeling of the Periodic Wear Process in Elastic Contact between Two Bodies. Journal of Friction and Wear 29 (2), 81-85 (2008)

2. C. I. Barbinta, et al., Wheel-rail contact modelling and analysis, considering profiles types and lateral displacement. Transport Research Arena: $5^{\text {th }}$ Conference: Transport Solutions from Research to Deployment, Paris: 14.04.2014 - 17.04.2014, France: Paris, Accession Number: 01540797 (2014)

3. R. Enblom, M. Berg, Simulation of railway wheel profile development due to wearinfluence of disc braking and contact enviroment. Wear: an international journal on the science and technology of friction, lubrication and wear 258, 1055-1063 (2004)

4. J. Gerlici, T. Lack, Contact of rail wheelset and track: (Žilina, University of Žilina, EDIS, 200 p., ISBN 80-710000-317-5, 2004)

5. L. Jakubovičová, M. Sága, Computational analysis of contact stress distribution in the case of mutual stewing of roller bearing rings. Novel Trends in Production Devices and Systems, Applied Mechanics and Materials 474, 363-368 (2014)

6. Z. Pelagić, M. Nágel', M. Žmindák, D. Riecky, Wear simulation modeling by using the finite element method. Manufacturing technology: Journal for science, research and production 15 (2), 191-195 (2015)

7. T. Lack, J. Gerlici, Contact area and normal stress determination on railway wheel / rail contact. Communications - scientific letters of the University of Žilina 7 (2), 38-45 (2005)

8. M. Svoboda, J. Soukup, Dynamic Measurement of Four-Axle Railway Wagon. Manufacturing technology: Journal for science, research and production 13 (4), 552-558 (2013)

9. J. Dižo, S. Steišunas, M. Blatnický, Simulation analysis of the rail vehicle running with wheel flat. Manufacturing technology: Journal for science, research and production $\mathbf{1 6}$ (5), 889-896 (2016)

10. V. Hauser, et al., Impact of three axle boxes bogie to the tram behavior when passing curved track. Procedia Engineering 192, 295-300 (2017)

11. R, Kohár, S. Hrček, Dynamics analysis of rolling bearings with an elastic cage. Modern methods of construction design, Cham: Springer, ISBN 978-3-319-05202-1, 249-254 (2014)

12. T. Lack, J. Gerlici, The FASTSIM method modification in speed up the calculation of tangential contact stresses between wheel and rail. Manufacturing technology: Journal for science, research and production 13 (4), 486-492 (2013)

13. T. G. Paerce, N. D. Sherrat, Prediction of wheel profile wear. Wear 144, 343-351 (1991)

14. M. Žmindák, Z. Pelagić, J. Soukup, Analysis of fiber orientation influence to dynamic properties of composite structures. Manufacturing technology: Journal for science, research and production 15 (3), 490-494 (2015) 